\title{
The experience of setting up a resident-managed Acute Pain Service: a descriptive study
}

Tommaso Borracci ${ }^{1}$, Daniela Prencipe ${ }^{1}$, Anita Masotti ${ }^{1}$, Alessandra Nella', Germana Tuccinardi ${ }^{2}$, Lucia Margiacchi ${ }^{1}$, Gianluca Villa ${ }^{1,2}$, Fulvio Pinelli', Stefano Romagnoli ${ }^{1}$, Angelo Raffaele De Gaudio ${ }^{1,2}$ and Giovanni Zagli ${ }^{*}$

\begin{abstract}
Background: The benefits of an Acute Pain Service (APS) for pain management have been widely reported, but its diffusion is still limited. There are two APS models: anesthesiologist-based and a nurse-based model. Here we describe the development of a different APS model managed by anesthesia residents, and we report the first year of activity in a tertiary Italian university hospital (Careggi University Hospital, Florence, IT).

Methods: Patients were included in the APS were those undergoing abdominal and urologic surgery causing moderate or severe postsurgical pain. The service was provided for patients, beginning upon their exit from the operating room, for 4, 12, 24 and $48 \mathrm{~h}$ for iv, and up to $72 \mathrm{~h}$ for epidural therapy. Vital signs, static/dynamic VAS, presence of nausea/vomiting, sedation level, and Bromage scale in case of epidural catheter, were monitored.

Results: From September 2013 to April 2015, a total of 1054 patients who underwent major surgery were included in the APS: 542 from abdominal surgery and 512 from urological surgery. PCA and epidural analgesia were more adopted in general surgical patients than in urology ( $48 \%$ vs $36 \%$ and $15 \%$ vs $2 \%$, respectively; $P<0.0001$ ). Patients who underwent to abdominal surgery had a significantly higher self-administration of morphine (30.3 vs $22.7 \mathrm{mg} ; P=0.0315$ ). Elastomeric pump was the analgesic of choice in half of the urologic patients compared to a quarter of the general surgical patients $(P<0.0001)$. Among the different surgical techniques, epidural analgesia was used more in open (16.5\%) than in videolaparoscopic (1.9\%) and robotic technique (1.1\%), whereas PCA was predominant in videolaparoscopic (46.5\%) and robotic technique (55.5\%) than in open technique (31.4\%).
\end{abstract}

Conclusions: The creation of APS, managed by anesthesia residents, may represent an alternative between specialist-based and nurse-based models.

\section{Background}

Perioperative pain can be defined as pain present in surgical patients, caused by a pre-existing disease, the surgical procedure, or by the simultaneous presence of causes correlated with the surgery or pathology [1]. Since the first experience of treatment units for acute pain management (Acute Pain Service, APS) [2, 3], the benefits of a dedicated, multidisciplinary organization for pain management have been reported and accepted [4], even in terms of cost-effectiveness [5]. The Italian Society of

\footnotetext{
* Correspondence: giovanni.zagli@unifi.it

'Department of Anaesthesia and Intensive Care, Azienda

Ospedaliero-Universitaria Careggi, Florence, Italy

Full list of author information is available at the end of the article
}

Anesthesia Analgesia Resuscitation and Intensive Care Medicine (SIAARTI) promoted the standardization of procedures, the use of patient-controlled analgesia (PCA) and epidural analgesia (EA), and the development of APS for the adequate treatment of postoperative pain $[1,6]$. Despite the existence in literature of guidelines for the management of postsurgical pain, its management still seem to be inadequate [7].

In a postoperative pain survey, Coluzzi and coworkers showed that postoperative pain continues to be under-managed in Italy: in a sample of 163 Italian hospitals (24.4\% of Italian public hospitals), only $41.7 \%$ had an organized APS, most frequently in university and teaching hospitals [8]. In a second survey made in 2012, 
Table 1 Baseline characteristics of patients included in APS

\begin{tabular}{|c|c|c|c|c|c|c|c|c|c|}
\hline & Overall & $\begin{array}{l}\text { General } \\
\text { surgery }\end{array}$ & Urology & $P$ & $\begin{array}{l}\text { Open } \\
\text { surgery }\end{array}$ & $\begin{array}{l}\text { Videolaparoscopic } \\
\text { surgery }\end{array}$ & $P$ & $\begin{array}{l}\text { Robotic } \\
\text { surgery }\end{array}$ & $P$ \\
\hline Number (\%) & 1054 & $542(51.4 \%)$ & $512(48.6 \%)$ & & 484 (45.9 \%) & 206 (19.6\%) & & $364(34.5 \%)$ & \\
\hline Age (years) & $62.6 \pm 14.8$ & $62.5 \pm 15.6$ & $62.7 \pm 13.9$ & 0.8816 & $63.1 \pm 14.9$ & $64 \pm 16.6$ & 0.6394 & $61.1 \pm 13.4$ & 0.1544 \\
\hline BMl & $25.6 \pm 4.2$ & $25.5 \pm 4.8$ & $25.8 \pm 3.4$ & 0.4678 & $25.8 \pm 4.2$ & $25.4 \pm 4.2$ & 0.3383 & $25.5 \pm 4.3$ & 0.4654 \\
\hline $\begin{array}{l}\text { Gender (male), } \\
\text { N (\%) }\end{array}$ & 640 (60.7 \%) & 264 (48.7 \%) & 376 (73.4 \%) & $<0.0001$ & 320 (66.1 \%) & 90 (43.7 \%) & $<0.0001$ & $230(63.2 \%)$ & 0.3841 \\
\hline $\begin{array}{l}\text { Duration of } \\
\text { surgery (min) }\end{array}$ & $265.2 \pm 134$ & $278.9 \pm 137.4$ & $250.2 \pm 129.1$ & 0.5363 & $264.4 \pm 124.6$ & $245.9 \pm 139$ & 0.2927 & $339 \pm 147.3$ & 0.0080 \\
\hline
\end{tabular}

Videolaparoscopic and robotic techniques were compared to the open technique (referral)

Continuous data are expressed as mean \pm standard deviation (SD). Statistical analysis: two-tailed Mann-Whitney test and two tails Fisher's exact test. $P$ significant if $<0.05$ (bold)

the sample included 289 hospitals $(43.3 \%$ of the Italian public hospitals), and results showed no substantial improvements since 2006 [9]. Thus, the correct management of post-operative pain is still a challenge in the Italian reality, and APS are not yet enough diffused.

It is possible to differentiate two main APS models: the first is the US model, which consists of anesthesiologistbased comprehensive pain management teams; the second is a nurse-based supervised APS, more diffused in European countries. Here we present the description of a different APS model and we report the first 12 months of activity.

\section{Methods}

In September 2013, an APS for the post-operative period was organized in a tertiary Italian university hospital (Careggi University Hospital, Florence, IT). The management of APS was performed by residents of anesthesia.

The model adopted was based on residents in anesthesia, the "hub" of the system. Every day, a resident of anesthesia was dedicated exclusively to the APS service from 8 am to $8 \mathrm{pm}$. During the night, the Intensive Care Unit (ICU) resident on duty carried out the APS, assuring continuity of care. Patients included in APS were those undergoing abdominal and urologic surgery causing moderate or severe postsurgical pain. Operations were classified into major, intermediate, and minor, depending on the degree of pain that might be expected [10]. According to pain treatment guidelines, patients were assigned to a different treatment protocol based on surgery and health status. Patients were enrolled in APS if they showed moderate or severe postsurgical pain, or if the senior anesthesiologist was not completely sure of the adequacy of analgesia.

The service included the compilation of special forms for each patient at intervals of time, beginning upon exit from the operating room to $4,12,24$ and $48 \mathrm{~h}$ for intravenous therapy, and up to $72 \mathrm{~h}$ for epidural therapy. Vital signs, static and dynamic VAS, presence of nausea/ vomiting, sedation level, and Bromage scale in case of epidural catheter, were monitored. For the realization of our APS, we initially used a paper database, stored in a file cabinet. Beginning in January 2015, after modification and optimization of the initial model, a digital database was created, and a laptop (connected to the hospital server) was used to record bedside data. The

Table 2 Analgesic drug dosages used in patients included in APS

\begin{tabular}{|c|c|c|c|c|c|c|c|c|}
\hline & $\begin{array}{l}\text { General surgery } \\
(N=542)\end{array}$ & $\begin{array}{l}\text { Urology } \\
(N=512)\end{array}$ & P & $\begin{array}{l}\text { Open surgery } \\
(N=484)\end{array}$ & $\begin{array}{l}\text { Videolaparoscopic } \\
\text { surgery }(N=206)\end{array}$ & $P$ & $\begin{array}{l}\text { Robotic surgery } \\
(N=364)\end{array}$ & $P$ \\
\hline Intraoperative morphine (mg) & $6.9 \pm 2$ & $6.6 \pm 2.2$ & 0.1613 & $6.7 \pm 2.4$ & $6.4 \pm 2$ & 0.4066 & $6.9 \pm 1.8$ & 0.2069 \\
\hline PCA, N (\%) & $262(48.3 \%)$ & $186(36.3 \%)$ & $<0.0001$ & $152(31.4 \%)$ & $94(45.6 \%)$ & 0.0005 & $202(55.5 \%)$ & $<0.0001$ \\
\hline $\begin{array}{l}\text { Patient-controlled morphine } \\
\text { administration (mg) }\end{array}$ & $30.3 \pm 21.3$ & $22.7 \pm 20.7$ & 0.0315 & $30.1 \pm 27.9$ & $35.6 \pm 33.8$ & 0.2928 & $20.2 \pm 21$ & 0.0039 \\
\hline Elastomeric pump, N (\%) & $140(25.8 \%)$ & $258(50.4 \%)$ & $<0.0001$ & $196(40.5 \%)$ & $64(31.1 \%)$ & 0.0205 & $140(38.5 \%)$ & 0.5708 \\
\hline Epidural catheter, N (\%) & $80(14.8 \%)$ & $10(2 \%)$ & $<0.0001$ & $80(16.5 \%)$ & $4(1.9 \%)$ & $<0.0001$ & $4(1.1 \%)$ & $<0.0001$ \\
\hline $\begin{array}{l}\text { Scheduled iv repeated } \\
\text { administration, } N(\%)\end{array}$ & 60 (11.1\%) & $58(11.3 \%)$ & 0.9223 & $56(11.6 \%)$ & $44(21.4 \%)$ & 0.0013 & $18(4.9 \%)$ & 0.0008 \\
\hline Ketorolac (mg) & $26.3 \pm 9.6$ & $24.7 \pm 12.6$ & 0.1985 & $24.6 \pm 11$ & $27.3 \pm 12.8$ & 0.1196 & $25.2 \pm 10.5$ & 0.6668 \\
\hline Paracetamol (gr) & $1 \pm 0.1$ & $1 \pm 0.1$ & 0.3536 & $1 \pm 0.2$ & $1 \pm 0.2$ & 0.8980 & $1 \pm 0.1$ & 0.1386 \\
\hline
\end{tabular}

Videolaparoscopic and robotic techniques were compared to the open technique (referral)

Continuous data are expressed as mean \pm standard deviation (SD). Statistical analysis: two-tailed Mann-Whitney test and two tails Fisher's exact test. $P$ significant if $<0.05$ (bold) 
patients' records were created directly using a pc in the operating room, and the resident on duty in the APS received data on a laptop through the hospital Wi-Fi connection.

The protocol included the following therapies:

- Levobupivacaine $0.125 \%$ + fentanyl $0.5 \gamma / \mathrm{ml}$, flow of $5 \mathrm{ml} / \mathrm{h}$, patient-controlled bolus of $5 \mathrm{ml}$ with a lockout of $30 \mathrm{~min}$;
- Elastomeric infusion pump (20 mg morphine diluted in $50 \mathrm{ml}$ of saline solution, nominal flow of $2 \mathrm{ml} / \mathrm{h}$ );

- PCA: $0.5 \mathrm{mg} / \mathrm{ml}$ of morphine, patient-controlled bolus of $2 \mathrm{ml}$ with a lock-out at $15 \mathrm{~min}$, no continuous infusion;

- Scheduled iv repeated administration: paracetamol (0.5-1 gr every 6-8 h, maximum 4 gr/day);

- Rescue dose (if VAS was greater than 4): ketorolac $30 \mathrm{mg}$, maximum dose $90 \mathrm{mg} /$ day.
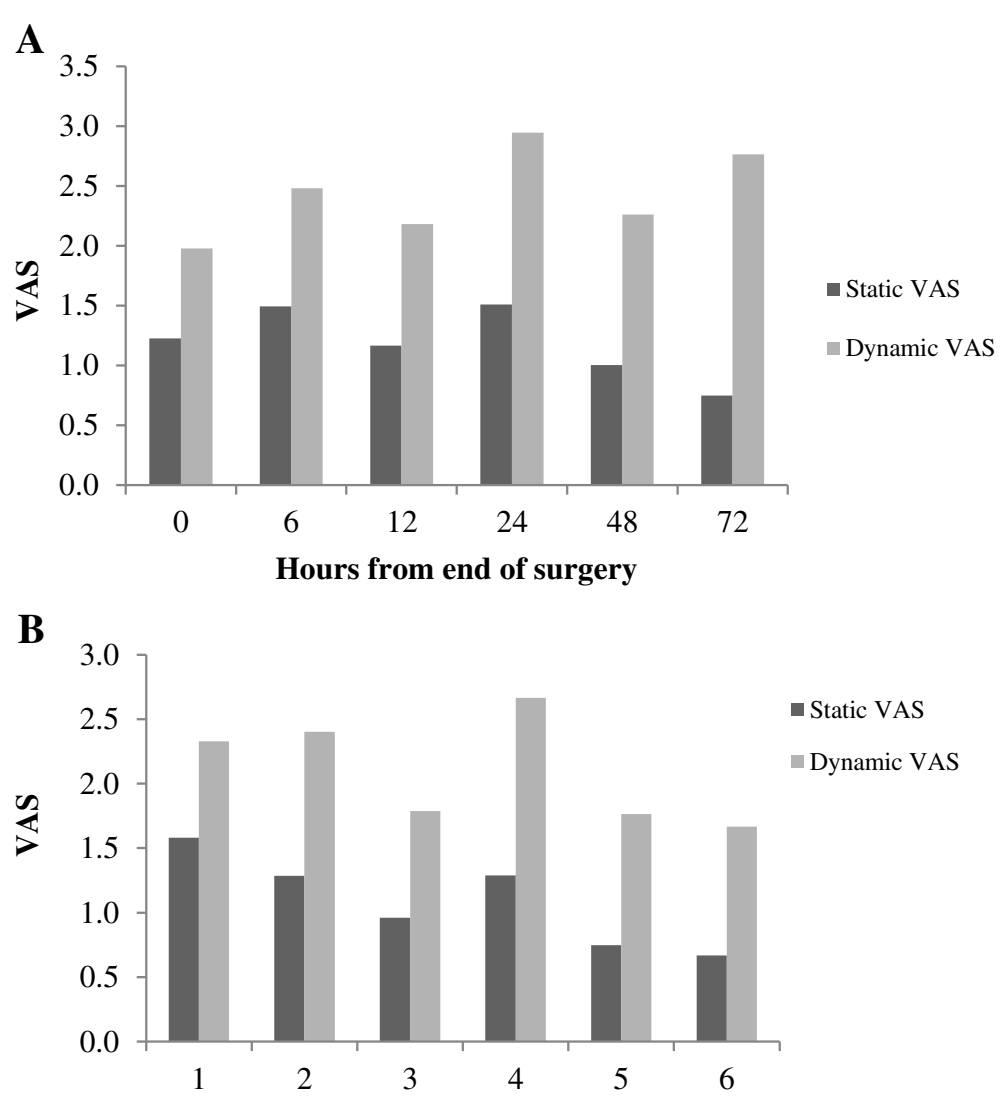

Hours from end of surgery

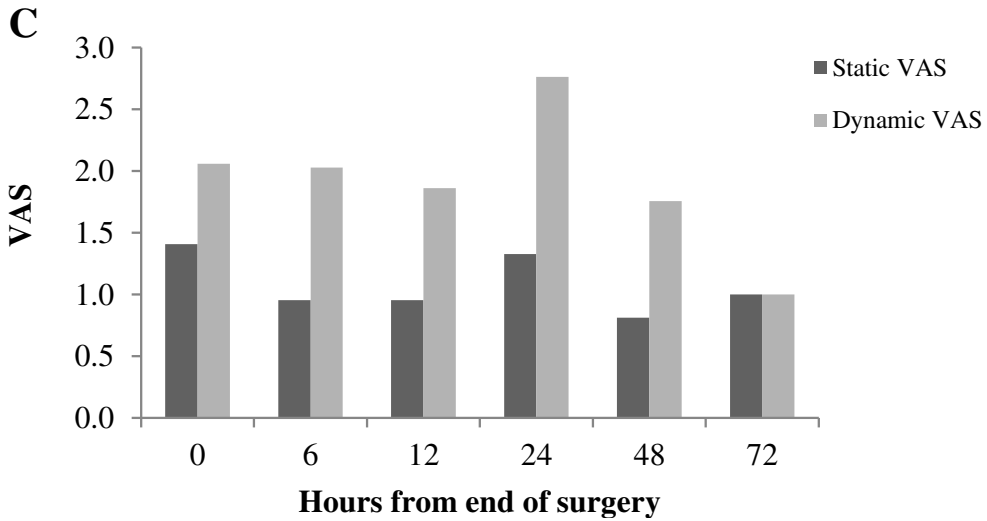

Fig. 1 Comparison of static and dynamic VAS in patients who underwent to open (panel a), videolaparoscopic (panel b) and robotic technique (panel c) 
This retrospective study was approved by the Institutional Ethics Committee of Careggi Hospital, which waived the need of informed consent for data publication due to the retrospective nature of the study and the anonymous data.

\section{Results}

From September 2013 through April 2015, a total of 1054 patients who underwent major surgery were included in the APS: 542 from abdominal surgery and 512 from urological surgery. As summarized in Table 1, the percentage of open surgical technique was similar in abdominal and urological patients, whereas the robotic technique was predominant in urology, and laparoscopy was predominant in general surgery. Whereas open technique percentage was similar among general surgery and urology ( $45 \%$ vs $47 \%$, respectively), percentage of videolaparoscopic technique resulted higher in general surgery ( $34 \%$ vs $4 \% ; P<0.0001$ ); on the contrary, robotic surgery was used more in urologic patients than in general surgery ( $49 \%$ vs $21 \%$ respectively; $P<0.0001$ ). Duration of surgery was similar among open (referral) and videolaparoscopic, whereas robotic technique resulted significantly longer $(P=0.0080)$ when compared with the referral technique (Table 1).

Table 2 summarizes the analgesic drug dosages and the devices used, an analysis based on general/urology and surgical techniques. Among general and urologic surgery, PCA and epidural analgesia were adopted more in general surgery than in urology (48\% vs $36 \%$ and $15 \%$ vs $2 \%$, respectively; $P<0.0001)$. On average, general surgical patients also had a significantly higher selfadministration of morphine bolus than urologic patients (30.3 vs $22.7 \mathrm{mg} ; P=0.0315)$. Elastomeric pump was the analgesic of choice in half of the urologic patients compared to a quarter of the general surgical patients $(P<0.0001)$. Among the different surgical techniques, epidural analgesia was used more in open $(16.5 \%)$ than in videolaparoscopic (1.9\%) and robotic technique $(1.1 \%)$, whereas PCA was predominant in
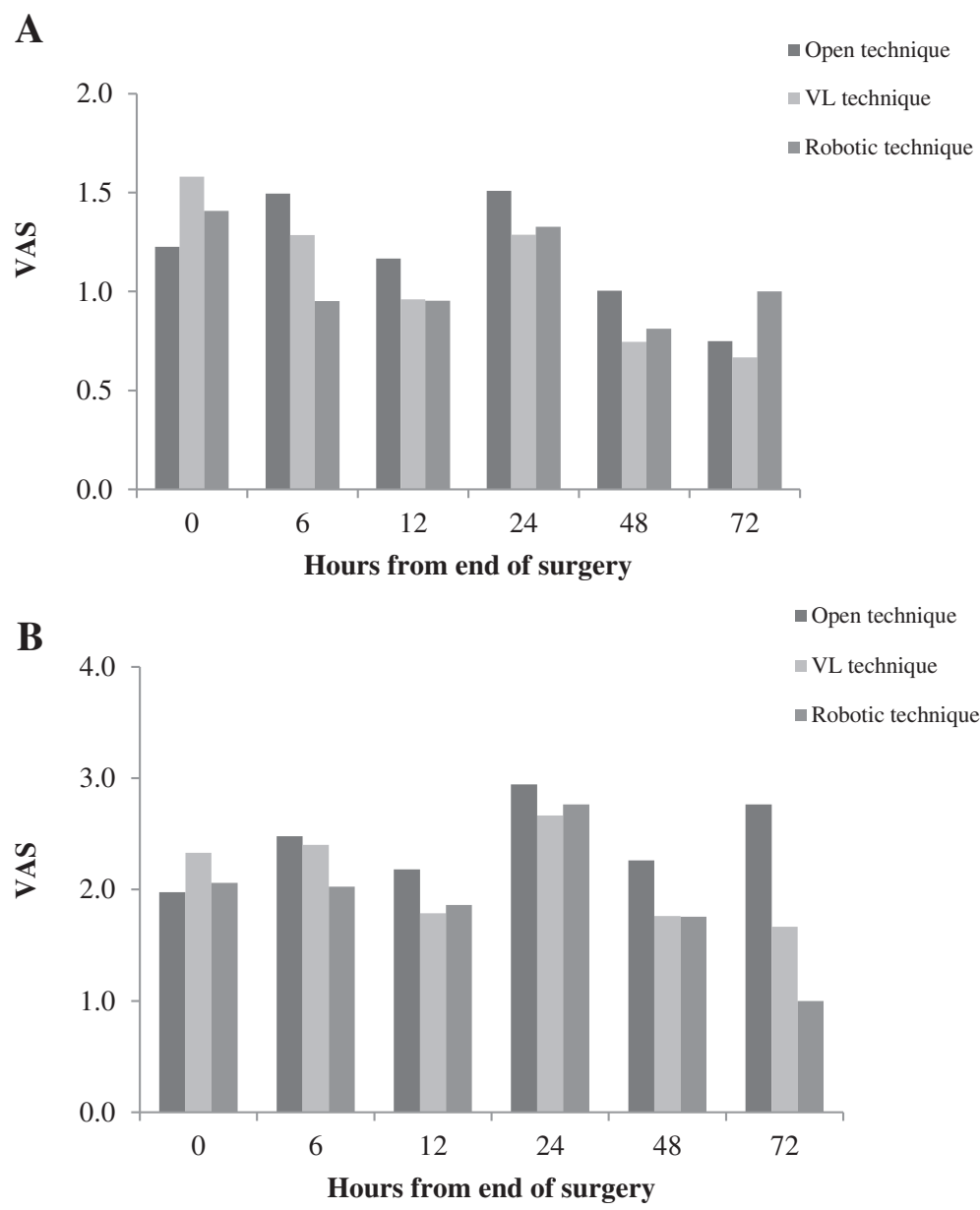

Fig. 2 Comparison of static (panel a) and dynamic VAS (panel b) in open, videolaparoscopic and robotic surgery in patients who underwent to abdominal surgery 
videolaparoscopic (46.5\%) and robotic technique (55.5\%) compared to open technique (31.4\%) (Table 2).

As shown in Fig. 1, time course of VAS measurements showed a progressive reduction of level of pain. However, dynamic VAS remained significantly higher than the static VAS $(P<0.0001$, Mann-Whitey test $)$ in all three surgical techniques. The comparison between static and dynamic VAS in abdominal surgery (Fig. 2) and urological surgery (Fig. 3) showed that postoperative pain resulted similar among the different surgical techniques.

\section{Discussion}

The creation of an APS permitted us to follow patients during the first 3 days after surgery, as well as to study and analyze the typology of patients, technique of analgesia, appropriateness of therapy. The recent survey of Coluzzi and co-Authors [9] underlined that postoperative pain is still under-treated, and confirmed that diffusion APS in Italy is still lower than other European countries [11]. Our results, when compared with POPSI2 study [9], showed that the switch from elastomeric pump to PCA in our hospital can be considered satisfactory. However, even if our percentage of epidural catheters resulted acceptable compared with the data of Coluzzi and co-Workers, the finding that patients undergoing general surgery with open technique and managed with PCA self-administrated more morphine than urologic patients (Table 2), may suggest that we should increase the number of epidural catheters in general surgery. Notably, we observed that we did not use the as-needed analgesia modality anymore, which resulted to be highly prescribed in the survey (19\%) [9].

Concerning the different APS models, the US one (anesthesiologist-base) is effective but expensive, whereas the nurse-based supervised APS is a low-cost model in terms of the role of the anesthesiologist, which essentially is to teach and train nurses, supervise the APS, and select
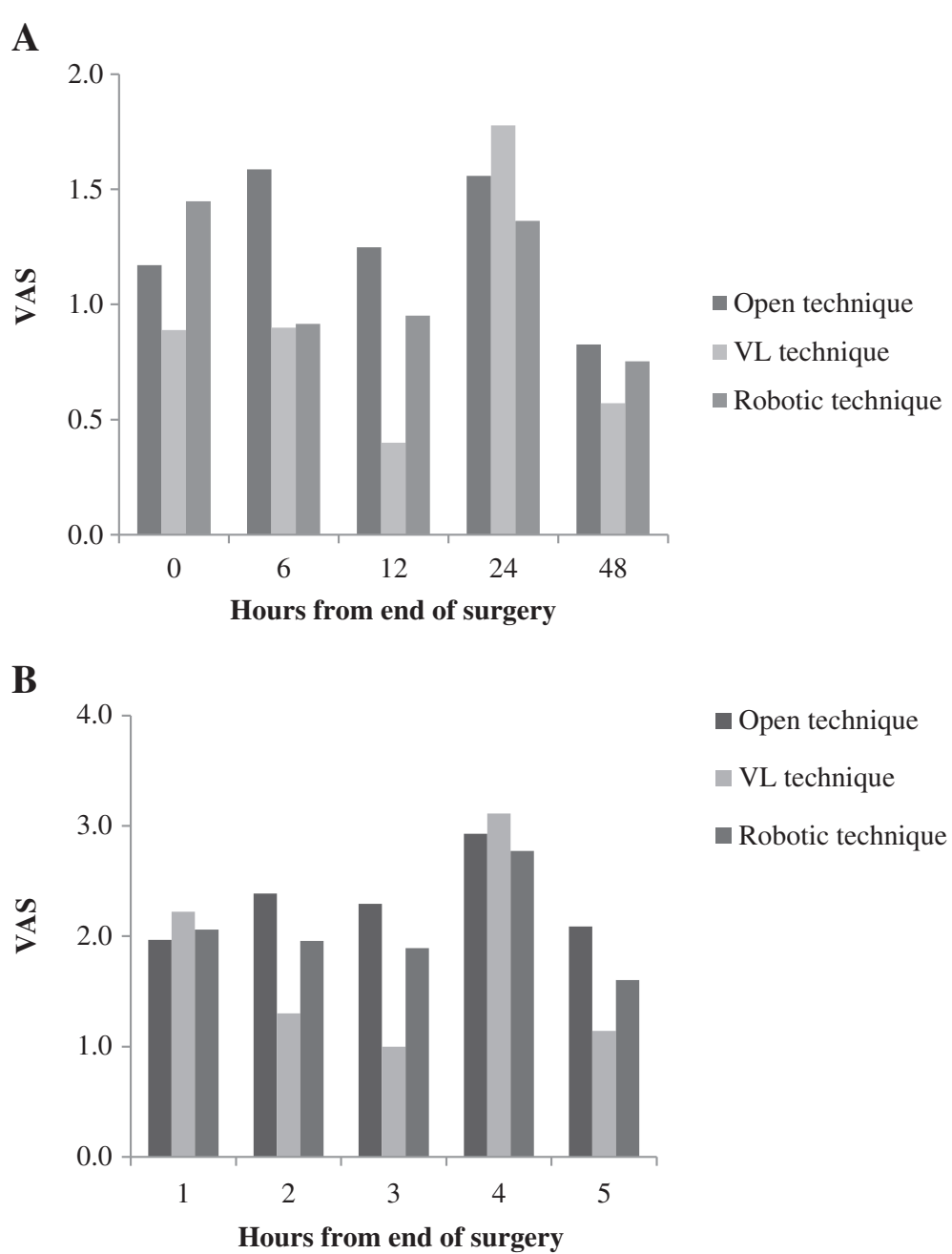

Fig. 3 Comparison of static (panel a) and dynamic VAS (panel b) in open, videolaparoscopic and robotic surgery in patients who underwent to urologic surgery 
patients for special pain therapies [12]. Our model, managed by residents of anesthesia supervised by the senior anesthesiologist, could be considered a third choice, in which anesthesia residents, who have more professional skills than nurses, and can permit the early identification of patients who are developing post-operative complications (e.g. sepsis). In our experience, the ongoing development of an electronic database has represented an important progress in APS activity, as previously reported in a similar experience [13]. The use of a digital database, thereby updating data at the bedside with a laptop, permitted real-time analysis, data uniformity, and handover facilitation, in particular before the night shift.

Limitations of the present article must be discussed. First, as mentioned above, the lack of historical control group did not permit any comparison in terms of efficacy of analgesic therapy, appropriateness of devices used, complications rate. Second, we were not able to compare different model of APS organization, since this was our first experience. Finally, in consideration of the parameter used in pain evaluation (e.g. VAS), our sample size should be considered limited.

\section{Conclusions}

The organization of APS should be a primary goal in post-operative care. Our experience suggests that the creation of APS model, managed by anesthesia residents, may represent an alternative between the US one (expensive, thus difficult to apply in Italian Healthcare System) and the nurse-based model.

\section{Abbreviations \\ APS: Acute Pain Service; ICU: Intensive Care Unit; PCA: Patient Controlled Analgesia.}

\section{Competing interests}

The authors declare that they have no competing interests.

\section{Authors' contributions}

TB, DP and ARDG organized the APS; TB, AM, AN, GT and GZ reviewed the literature; AM, AN, GT, GV and LM collected data; GV and GZ performed statistical analysis; AM, GT, FP, SR and GZ wrote the draft; all authors revised the manuscript and approved the final version.

\section{Acknowledgments}

This study was supported by institutional funds only. Authors are grateful to Daniele Pecoraro, a professional nurse of our hospital, who realized the electronic database for APS activity.

\section{Author details}

'Department of Anaesthesia and Intensive Care, Azienda Ospedaliero-Universitaria Careggi, Florence, Italy. ${ }^{2}$ Department of Health Science, University of Florence, Florence, Italy.

Received: 19 September 2015 Accepted: 16 February 2016

\section{- 10.0}

\section{References}

1. Savoia G, Alampi D, Amantea B, Ambrosio F, Arcioni R, Berti M, et al. Postoperative pain treatment SIAARTI Recommendations 2010. Short version. Minerva Anestesiol. 2010;76(8):657-67.
2. Ready LB, Oden R, Chadwick HS, Benedetti C, Rooke GA, Caplan R, et al. Development of an anesthesiology-based postoperative pain management service. Anesthesiology. 1988;68(1):100-6.

3. Rawal N, Berggren L. Organization of acute pain services: a low-cost model. Pain. 1994;57(1):117-23.

4. Bardiau FM, Braeckman MM, Seidel L, Albert A, Boogaerts JG. Effectiveness of an acute pain service inception in a general hospital. J Clin Anesth. 1999:11(7):583-9.

5. Stadler M, Schlander M, Braeckman M, Nguyen T, Boogaerts JG. A cost-utility and cost-effectiveness analysis of an acute pain service. J Clin Anesth. 2004;16(3):159-67.

6. Savoia G, Ambrosio F, Paoletti F, Bertini L, Mattia C, Amantea B, et al. SIAARTI recommendations for the treatment of postoperative pain. Minerva Anestesiol. 2002;68(10):735-50.

7. Dunwoody CJ, Krenzischek DA, Pasero C, Rathmell JP, Polomano RC. Assessment, physiological monitoring, and consequences of inadequately treated acute pain. J Perianesth Nurs. 2008;23(1 Suppl):S15-27.

8. Coluzzi F, Savoia G, Paoletti F, Costantini A, Mattia C. Postoperative pain survey in Italy (POPSI): a snapshot of current national practices. Minerva Anestesiol. 2009;75(11):622-31.

9. Coluzzi F, Mattia C, Savoia G, Clemenzi P, Melotti R, Raffa RB, et al. Postoperative Pain Surveys in Italy from 2006 and 2012: (POPSI and POPSI-2). Eur Rev Med Pharmacol Sci. 2015;19(22):4261-9.

10. Rosenquist RW, Rosenberg J. Postoperative pain guidelines. Reg Anesth Pain Med. 2003;28(4):279-88.

11. Nielsen PR, Christensen PA, Meyhoff CS, Werner MU. Post-operative pain treatment in Denmark from 2000 to 2009: a nationwide sequential survey on organizational aspects. Acta Anaesthesiol Scand. 2012;56(6):686-94.

12. Rawal N. Organization, function, and implementation of acute pain service. Anesthesiol Clin North America. 2005;23(1):211-25.

13. Love BL, Jensen LA, Schopflocher D, Tsui B. The development of an electronic database for Acute Pain Service outcomes. Pain Res Manag. 2012;17(1):25-30.

Submit your next manuscript to BioMed Central and we will help you at every step:

- We accept pre-submission inquiries

- Our selector tool helps you to find the most relevant journal

- We provide round the clock customer support

- Convenient online submission

- Thorough peer review

- Inclusion in PubMed and all major indexing services

- Maximum visibility for your research

Submit your manuscript at www.biomedcentral.com/submit
) Biomed Central 